\title{
The Relationship Between Age and Mental Health Among Adults in Iran During the COVID-19 Pandemic
}

\author{
Jiyao Chen ${ }^{1}$ - Stephen X. Zhang ${ }^{2}$ (D) Yifei Wang ${ }^{3}$ - Asghar Afshar Jahanshahi ${ }^{4,5}$. \\ Maryam Mokhtari Dinani ${ }^{6} \cdot$ Abbas Nazarian Madavani $^{7} \cdot$ Khaled Nawaser $^{8}$
}

Accepted: 3 June 2021 / Published online: 22 June 2021

(C) The Author(s), under exclusive licence to Springer Science+Business Media, LLC, part of Springer Nature 2021

\begin{abstract}
The evidence on the predictors of mental health in the COVID-19 pandemic has revealed contradictory findings, which prevent effective screening for mental health assistance. This study aims to identify the predictors of mental health issues, specifically examining age as a nonlinear predictor. Based on a survey of 474 adults using snowball sampling under the COVID-19 pandemic during April 1th-10th, 2020, in Iran, we found that age had a curvilinear relationship with nonsomatic pain, depression, and anxiety. Specifically, it predicted pain, depression, and anxiety disorders, negatively among adults younger than 45 years, yet positively among seniors older than 70 years. Adults who were female, were unsure about their chronic diseases, or exercised less were more likely to have mental health issues. This study, being the first paper to examine age curvilinearly, suggests future research to pay more attention to nonlinear predictors of mental health disorders in the COVID-19 pandemic.
\end{abstract}

Keywords Nonsomatic pain · Depression · Anxiety · Distress · Age $\cdot$ Curvilinear relationship

The COVID-19 pandemic has led to the unprecedented disruption of people's work and life (Zhang et al., 2020a, b, c, d) and triggered widespread mental health issues (Xiang et al., 2020). A burgeoning body of research is unveiling the risk factors for mental disorders under the COVID-19 pandemic (Chen et al., 2020; Yáñez et al., 2020); however, the evidence on individual demographics as predictors is mixed. For example, some studies have found that age affected mental disorders negatively (González-Sanguino et al., 2020; Moccia et al., 2020; Tang et al., 2020; Wang et al., 2020), but other studies have found the relationship between age and mental disorders to be positive (Qiu et al., 2020) or insignificant (Meng et al., 2020; Song et al., 2020; Zhang et al., 2020a, b, c, d). The conflicting evidence prevents the effective identification of the mentally vulnerable people during the ongoing COVID-19 pandemic.

Stephen X. Zhang

stephen.x.zhang@gmail.com

Extended author information available on the last page of the article 
This study aims to investigate the role of age and other predictors on adults' nonsomatic pain, depression, anxiety, and distress. To this end, this study does not assume the relationship between age and mental health disorders to be linear. Instead, it examines its second-order term, using a sample of adults across a wide spectrum of ages from 20 to 79 . Furthermore, this study tests the predictors of individuals' work situation, daily exercise hours, and the number of times out of home per day. Finally, some studies have found individuals among both healthcare workers and the general population who were unsure of their COVID-19 infection status had more mental health issues (Jahanshahi, Dinani, Madavani, Li, \& Zhang et al., 2020a, b, c, d). Following this line of thinking, this study tests whether individuals were unsure of their chronic diseases as a predictor of mental health issues.

The predictors in our study help to further the advancement of ongoing research about the predictors of mental health issues during the COVID-19 pandemic (Dai et al., 2020). Our results provide some reconciliation of the conflicting findings in this rapidly growing body of literature and provide new directions for future research regarding specific risk factors and their boundary conditions to screen people in greater need of prioritized mental healthcare support.

\section{Methods}

\section{Context}

This study was conducted during the COVID-19 outbreak in Iran, one of the worst-hit countries by COVID-19 since January 2020. People in Iran faced some unique challenges such as sanctions and economic slowdown, lack of medical equipment and supplies, and the government's inability to enact effective social distancing measures, all of which may contribute to the mental vulnerabilities of adults in Iran under the COVID-19 pandemic. First, the Iranian economy has been under long-standing US-led sanctions. Moreover, a month before the first confirmed COVID-19 cases, Iran has been further isolated from the international financial markets, due to the claimed failure of Iran to comply with international anti-terrorism financing rules and norms. The severe sanctions have made it difficult for the health sectors in Iran to obtain medical equipment including even basic personal protective equipment (PPE) (Yoosefi Lebni et al., 2020). As a result, the isolated medical supply system in Iran faced severe shortages in both private and public health systems under the COVID-19 crisis (Ahorsu et al., 2020). As a result, healthcare workers did not have access to sufficient personal protective equipment and had to make their own gowns and marks during the pandemic (Zhang et al., 2020a, b, c, d).

Second, the healthcare system in Iran suffers from a lack of modern technologies, equipment, and devices necessary to provide sufficient healthcare capacities to deal with the infected cases during the COVID-19 pandemic (Aman, 2020; Zhang et al., 2020a, b, c, d). And evidence has shown that people in Iran suffered from higher distress than people in China during the COVID-19 pandemic (Jahanshahi et al., 2020).

Third, due to the difficult economic situations in Iran, it is hard to implement prolonged mandatory quarantine to effectively contain the spread of COVID-19 cases. Quarantine at home became especially challenging for people in low- and middle-class households, which experienced high inflation rates in the COVID-19 outbreak. The quick spread of COVID-19 in Iran has led to fears, worries, and anxiety among the general population, regardless of their 
gender and age (Ahorsu et al., 2020). Moreover, some government officials downplayed the severity of the early COVID-19 cases to the public, who subsequently developed a lack of trust with the published COVID-19 data, fueling rumors that confound the anxiety of the adults in Iran.

\section{Data Collection}

Data in this cross-sectional study were collected through an online survey via social media platforms, e.g., Telegram, Instagram, and WhatsApp, from April 1 to April 10, 2020 , in Iran. Iran passed the peak of its COVID-19 pandemic with 3111 new infection cases on April 2 and had a total of 68,192 confirmed cases and 4232 deaths of COVID-19 on April 10, 2020. The survey was originally in English and then translated to the official language of Iran (Persian). It was pretested among 10 professionals in several industries and approved by the research ethics committee of the Iranian Sport Sciences Research Institute (IR.SSRI.REC.1389.685). Participation was voluntary, and all participants agreed, with their informed consent, to complete the survey. We guaranteed the anonymity and strict confidentiality of responses and targeted working adults older than 18 years in Iran. Based on the number of active users and social media groups, our survey could reach about 980 people. We received 474 usable responses, resulting in a response rate of $48.37 \%$. The participants worked in banking, education, finance, insurance, manufacturing, services, mining, and oil and gas sectors from all 31 provinces of Iran.

\section{Variables}

Participants reported their demographic characteristics such as exact age, gender, marital status, and working situation. Participants also reported whether they had chronic diseases (no, unsure, yes), daily exercise hours, and the number of times they left home per day in the past week.

The outcome variables included nonsomatic pain, depression, anxiety, and distress. Nonsomatic pain was measured by three items including "For the past week I feel I am in agony" $(0=$ never, rarely, to $3=$ always; Cronbach's $\alpha=0.75)$ (Keller $\&$ Nesse, 2006). Depression was measured by Patient Health Questionnaire-2 (PHQ-2) $(0=$ never, rarely, to $3=$ always; $\alpha=0.77$ ) with a cut-off point of 3 . Anxiety was measured by the Generalized Anxiety Disorder-2 scale (GAD-2) $(0=$ never, rarely, to $3=$ always; Cronbach's $\alpha=0.76)$ with a cut-off point of 3 (Kroenke et al., 2009). Distress was measured by K6, the six-item Kessler mental distress scale $(0=$ never to $4=$ almost all of the time; Cronbach's $\alpha=0.90)$ with a cutoff point of 13 (Kessler et al., 2002). All scales show internal consistency as their Cronbach's alphas are greater than 0.7 (Cronbach, 1951).

\section{Data Analysis Approach}

We used Stata 16.0 for descriptive statistics and to predict pain by ordinary least squares regression and depression, anxiety, and distress by logistic regression with a $95 \%$ confidence level. 


\section{Results}

\section{Descriptive Findings on the Covariates}

Table 1 shows that $37.4 \%$ of the 474 participants were younger than 40 years old, $50.2 \%$ were between 40 and 59, and $12.4 \%$ were above 60 years. Over half $(51.3 \%)$ were female, and $87.1 \%$ did not have chronic diseases, $3.0 \%$ were unsure, and $9.9 \%$ had chronic diseases. Over half $(56.3 \%)$ did not do any exercise in the last week, $37.3 \%$ exercised on average about one hour daily, and $6.4 \%$ exercised two hours or more per day. $44.9 \%$ worked at home in the past week, $26.8 \%$ worked in the office, and $28.3 \%$ did not work during the epidemic. $15.6 \%$ did not leave home in the last week, $37.8 \%$ left home once daily, and $46.6 \%$ left twice or more per day. Tehran, Iran's capital, is the epicenter of the Iran COVID-19 outbreak in April 2020, and $99(20.7 \%)$ of our data were collected from this city.

\section{Descriptive and Comparative Findings on the Outcome Variables}

Less than one in ten $(8.65 \%)$ participants felt nonsomatic pain most of the time. About one fifth surpassed the cut-off of depression (21.94\%), anxiety (21.10\%), and distress (14.77\%). By comparing our findings with those in 12 studies using similar measurements, we found that overall, the Iranian adults' mental health conditions were comparable or worse than those in several samples in China, Spain, and Italy with a few exceptions (see Table 2 for a summary). For example, the proportion of adults with depression and anxiety disorders in our sample was similar to or worse than the samples from China and Spain during the COVID-19 outbreak with four exceptions (see Song et al., 2020; González-Sanguino et al., 2020; Ni et al., 2020). The adults in our sample were less likely to have depression and anxiety disorders than those in a sample of seniors older than 60 years in China (Meng et al., 2020) and of younger adults aged 18-30 years in the USA (Liu, Zhang et al., 2020a, b, c, d), and to have more depression than the adults in two relatively small samples in China (Guo et al., 2020; Zhang et al., 2020a, b, c, d). Additionally, in our sample, the proportion of adults with distress disorder was similar or worse than those in several samples in China and Italy, but lower than that in a sample of adults in the USA in late April 2020 (Twenge \& Joiner, 2020).

Two recent studies found that the Iranian adults' mental health symptoms measured by DASS-21 during the COVID-19 pandemic were even worse than our findings (Khademian et al., 2021; Moghanibashi-Mansourieh, 2020) (Table 2). For example, based on a sample of 1498 participants from April 18 to 28, 2020, Khademian et al. (2021) found that the prevalence of depression, anxiety, and distress are $34.7 \%, 31.8 \%$, and $24.6 \%$, respectively. The prevalence rates in the two studies were higher than that of our study perhaps because of the different measurements used. Some meta-analyses show that the prevalence of anxiety in Africa in studies using DASS-21 were significantly higher than those using GAD-7 (Chen et al., 2021).

\section{Predictors of Pain, Depression, Anxiety, and Distress}

First, adults' age had a curvilinear relationship with their pain, depression, and anxiety (for pain: $\mathrm{b}=0.0005,95 \% \mathrm{CI} 0.0001$ to $0.008, p=0.007$; for depression: $\mathrm{OR}=1.0020,95 \% \mathrm{CI}$ 1.0004 to $1.0035, p=0.009$; for anxiety: $\mathrm{OR}=1.0020,95 \%$ CI 1.0004 to $1.0035, p=0.015$ ). To show the curvilinear relationship, we plotted the mental health-age slope at varying ages in 


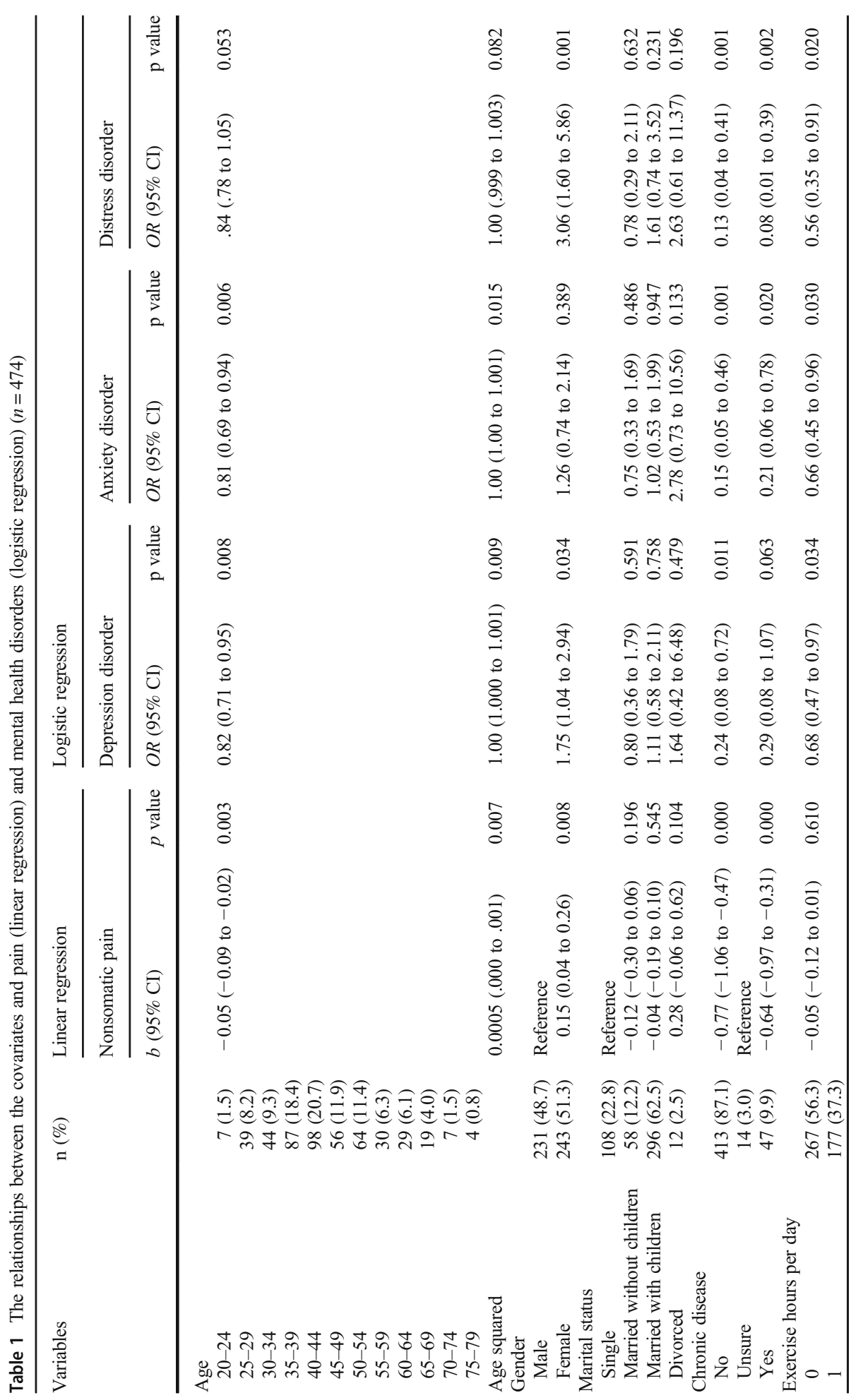




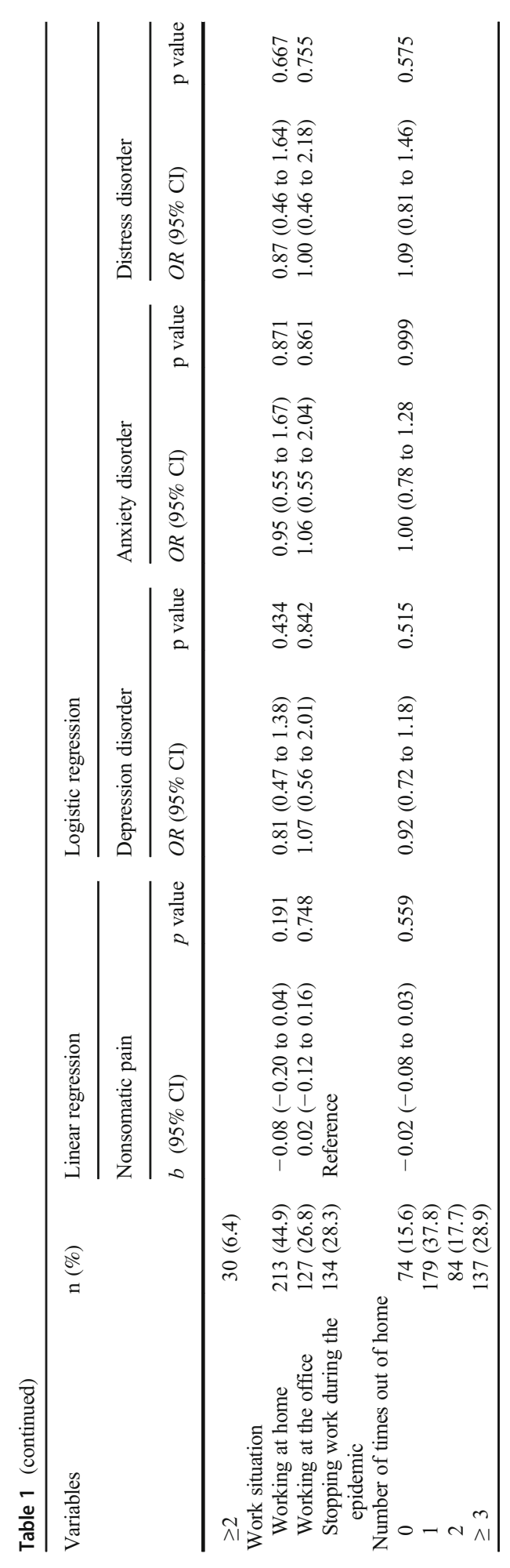




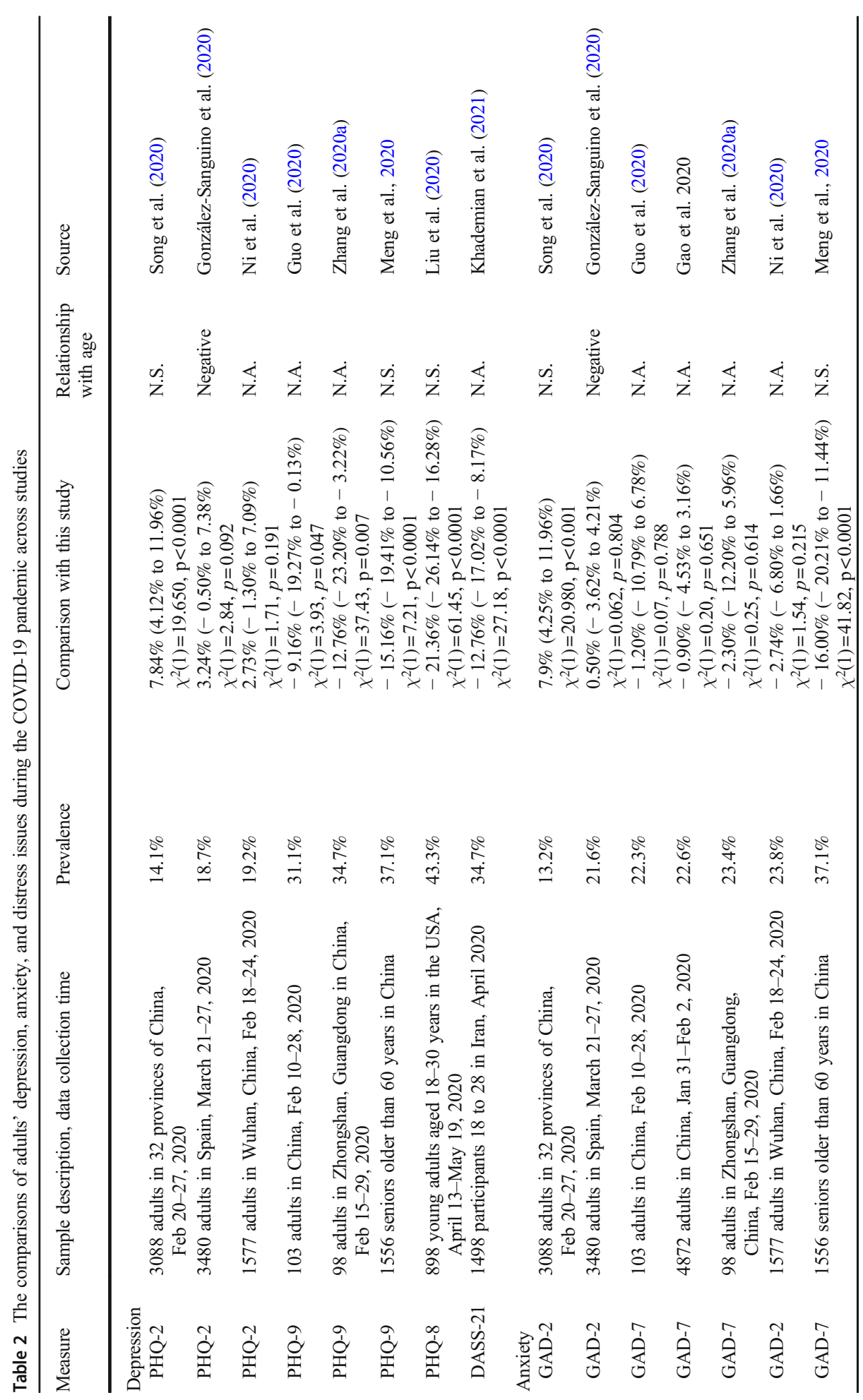




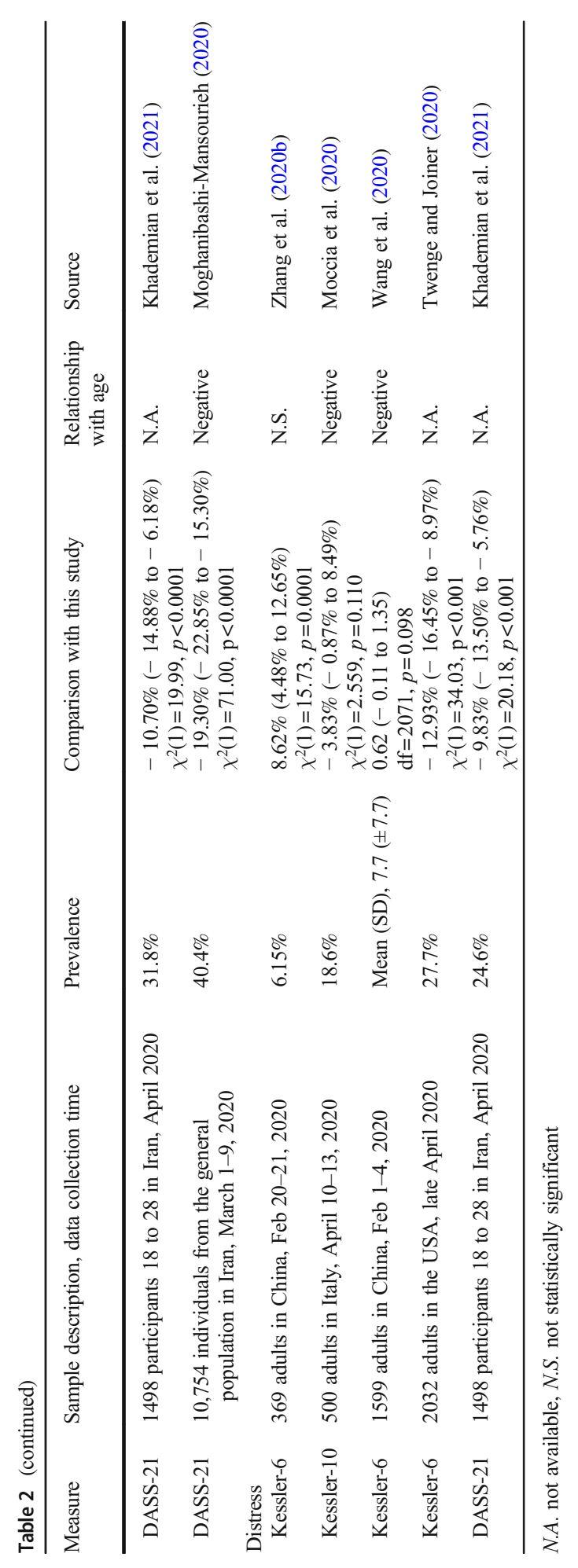


Fig. 1. Margin effect analyses showed that adults' age predicted pain negatively among the young (e.g., at 20 years old: $\mathrm{b}=-0.032,95 \% \mathrm{CI}-0.052$ to $-0.012, p=0.002$ ). On the contrary, adults' age predicted pain positively among seniors older than 70 years (e.g., at 75 years old: $\mathrm{b}=0.022,95 \%$ CI 0.002 to $0.042, p=0.030$ ). Similarly, age predicted depression negatively among younger people (e.g., at 20 years old: $\mathrm{OR}=0.97,95 \% \mathrm{CI} 0.95$ to $0.99, p=$ 0.006 ) and positively among older people (e.g., at 75 years old: $\mathrm{OR}=1.024,95 \%$ CI 1.01 to $1.05, p=0.042$ ). Finally, age predicted anxiety negatively among younger people (e.g., at 20 years old: $\mathrm{OR}=0.97,95 \%$ CI 0.96 to $0.98, p=0.000$ ) but not among older people (e.g., at 75 years old: $\mathrm{OR}=1.02,95 \%$ CI 0.99 to $1.04, p=0.214)$. To illustrate the curvilinear relationship between adult age and their mental issues, we show the predicted levels of nonsomatic pain and the predicted likelihood of depression, anxiety, and distress disorders over different ages in Fig. 2.

Second, females reported more pain ( $\mathrm{b}=0.15,95 \% \mathrm{CI} 0.039$ to $0.262, p=0.008)$ and were more likely to suffer from depression ( $\mathrm{OR}=1.75 ; 95 \% \mathrm{CI}, 1.04$ to $2.94 ; p=0.034)$ and distress disorders $(\mathrm{OR}=3.06 ; 95 \% \mathrm{CI}, 1.60$ to $5.86 ; p=0.001)$ than males.

Third, adults who were unsure whether they had chronic diseases experienced more pain than those with chronic diseases $(b=-0.64 ; 95 \% \mathrm{CI},-0.97$ to $-0.31 ; p=0.000)$ or without chronic diseases $(b=-0.77 ; 95 \% \mathrm{CI},-1.06$ to $-0.47 ; \mathrm{p}=0.000)$. Adults who were unsure whether they had chronic diseases were also more likely to suffer from anxiety issues compared with those with chronic diseases $(\mathrm{OR}=0.21 ; 95 \% \mathrm{CI}, 0.06$ to $0.80 ; p=0.020)$ or without chronic diseases $(\mathrm{OR}=0.15 ; 95 \% \mathrm{CI}, 0.05$ to $0.46 ; p=0.001)$. Furthermore, adults who were unsure whether they had chronic diseases were also more likely to have distress disorder, compared to those with chronic diseases $(\mathrm{OR}=0.08 ; 95 \% \mathrm{CI}, 0.01$ to $0.39 ; p=$ $0.002)$ or without chronic diseases $(\mathrm{OR}=0.13 ; 95 \% \mathrm{CI}, 0.04$ to $0.41 ; \mathrm{p}=0.001)$. Lastly, those
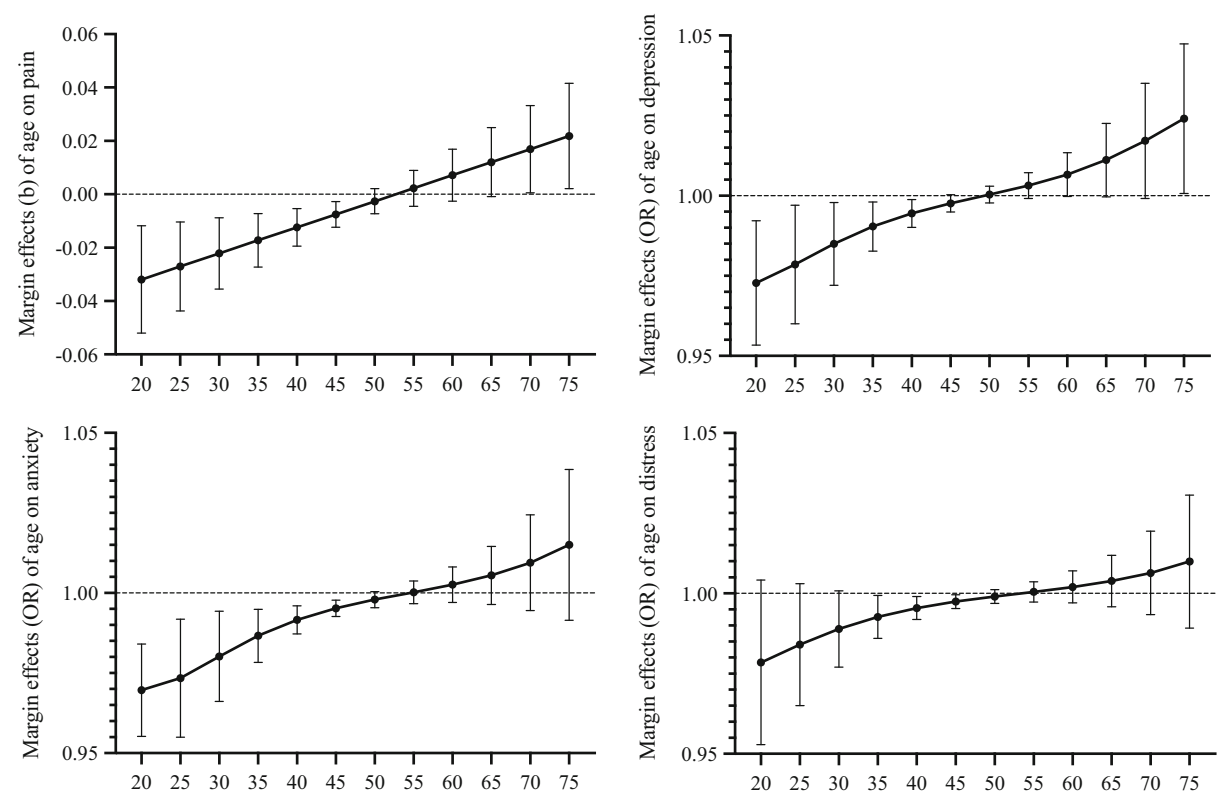

Fig. 1 The relationship between age and (a) nonsomatic pain, (b) depression, (c) anxiety, and (d) distress disorders by age 


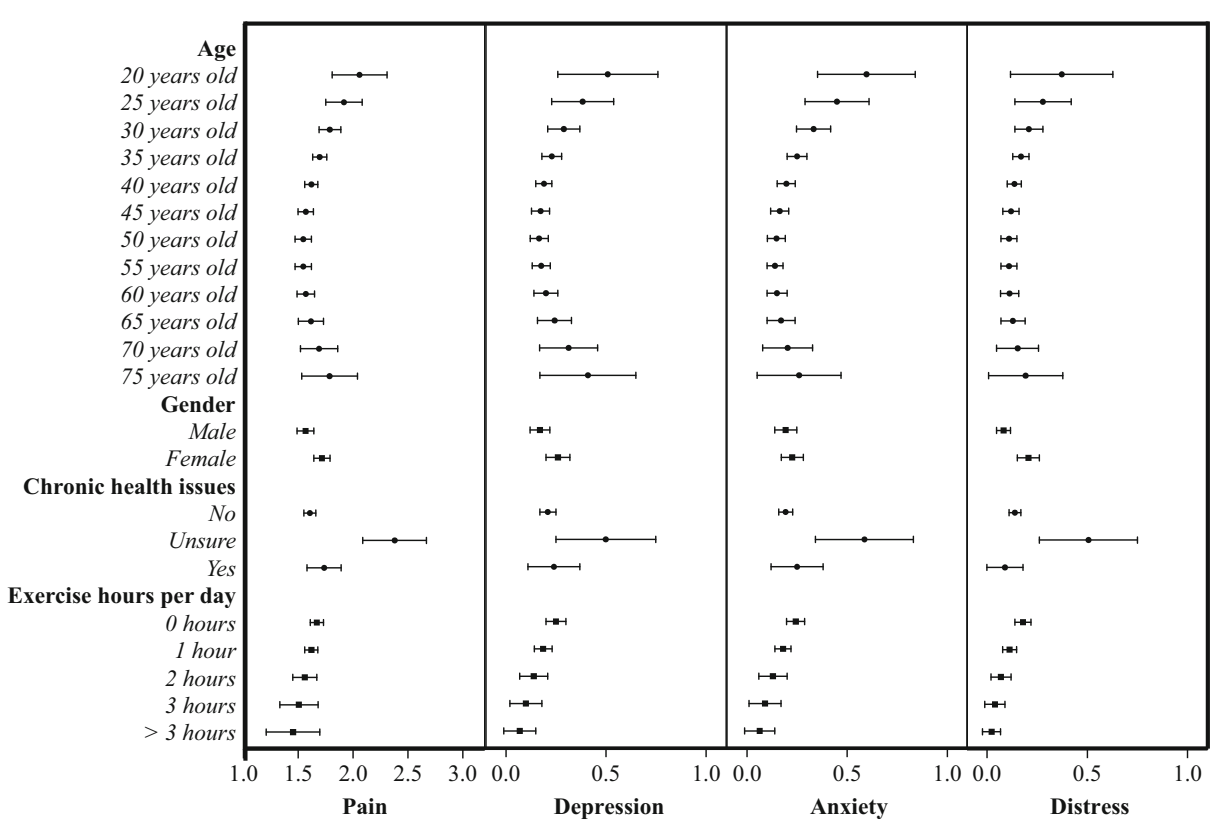

Fig. 2 The predicted levels of nonsomatic pain and the predicted likelihood of depression, anxiety, and distress disorders

who were unsure of their chronic diseases were more likely to suffer from depression than those without chronic diseases $(\mathrm{OR}=0.24 ; 95 \% \mathrm{CI}, 0.08$ to $0.72 ; p=0.011)$.

Lastly, adults who exercised more were less likely to experience mental health issues of depression $(\mathrm{OR}=0.68 ; 95 \% \mathrm{CI}, 0.47$ to $0.97 ; p=0.034)$, anxiety $(\mathrm{OR}=0.66 ; 95 \% \mathrm{CI}, 0.45$ to $0.96 ; p=0.030)$, or distress disorders $(\mathrm{OR}=0.56 ; 95 \% \mathrm{CI}, 0.35$ to $0.91 ; p=0.020)$.

\section{Discussion}

The accumulating body of studies on mental health under COVID-19 has begun to show conflicting results, particularly on the relationship between age and mental health disorders (Table 2). Several studies found a negative relationship (González-Sanguino et al., 2020; Moccia et al., 2020; Wang et al., 2020); other studies found the relationship to be positive (Qiu et al., 2020) or insignificant (Meng et al., 2020; Song et al., 2020; Zhang et al., 2020a, b, c, d). The contradictory evidence may result from (a) examining only a linear relationship and (b) the limited age range of the adults in the samples. With a wide range of ages from 20 to 79 , our study showed the relationship between age and pain, depression, and anxiety to be curvilinear (Fig. 1). In particular, age predicted pain, depression, and anxiety disorders negatively among adults younger than 45 years. Age was not a predictor of pain for ages 50-65 years, for depression for ages 45-70 years, or for anxiety for ages 50-80 years. Age predicted pain positively among those aged 70-79 years and depression disorder among those aged 7579 years. Such findings corroborate that the association between age and mental issues is negative among the younger population $(<45$ years), insignificant among the mid-aged $(50-$ 70 ish), and positive among seniors over 70 years. Seniors experienced more pain and depression, perhaps because they have a higher fatality rate during the COVID-19 outbreak 
and often have poor physical conditions and immune systems (Meng et al., 2020). In fact, a study of seniors older than 60 years (Meng et al., 2020) and a study of young adults between 18 and 30 years (Liu et al., 2020) showed that they were much more likely to suffer from depression disorder ( $37.1 \%$ and $43.3 \%$, respectively) than adults with varied ages in seven other studies (on average 20.9\%) (Table 2).

Our results suggest age remains an important predictor for mental health disorders during the COVID-19 pandemic. However, psychiatrists and mental health services should not use a specific age as either a positive or a negative predictor in screening and identifying people at risk. Instead, they should be mindful that the association between age and mental health issues could vary depending on the age range. The curvilinearity of age as a predictor needs to be considered before using it to identify the mentally vulnerable.

Our results showed that those who were unsure about their chronic diseases experienced more pain and were more likely to have depression, anxiety, and distress disorders than those who were sure about their status (either having or not having chronic diseases). Such a pattern is consistent with the findings that healthcare workers (Zhang et al., 2020a, b, c, d) and the general population who were not sure whether they were infected with the COVID-19 virus were more likely to have mental disorders than others who knew their status. In doing so, we extend the finding from COVID-19 to chronic diseases and suggest that future studies explore individuals' uncertainty on key factors as potential predictors of mental health.

Unlike past research that found gender was not a distress predictor in China (Zhang et al., 2020a, b, c, d) and Iran (Ahorsu et al., 2020; Jahanshahi et al., 2020), our Iranian sample showed that gender predicted distress, similar to an Italian sample (Moccia et al., 2020). In contrast to a study that found Chinese working adults who exercised less were happier with their life in a more severe COVID-19 prefecture (Zhang et al., 2020a, b, c, d), our results show that Iranian adults who exercised less were more likely to be depressed, anxious, and distressed, which corroborated the findings in a study of healthcare staff in Bolivia (Zhang et al., 2020a, b, c, d). All studies confirmed exercise time as a risk factor, but the direction of its effect may depend on the country and type of professionals. It is also worth noting that, in contrast to adults in China (Zhang et al., 2020a, b, c, d) and Iran before the peak of COVID-19 (Jahanshahi et al., 2020), those who stopped working were insignificantly different from those who worked either at home or at the office on reported pain, depression, anxiety, and distress. These studies show the importance of gender, exercise time, and working status in screening mentally vulnerable people in a crisis. The inconsistent findings call for more studies to investigate these predictors of mental health issues and their potential moderators such as country and stage of the pandemic.

This study has some limitations. First, due to the challenge of data collection during the COVID-19 crisis, we used convenient sampling; future studies with more representative sampling techniques could further examine age as a predictor of mental health. Second, the curvilinear relationship that we found was limited to our sample in Iran, and it is interesting to examine how it may vary in other populations. Further studies are required to determine how age plays out as a predictor to identify those who need mental healthcare.

Our study showed that Iranian adults after the peak of COVID-19 still suffered from depression, anxiety, and distress disorders to a similar or higher degree than people in other countries, except one study in the USA. The finding that the association between age and mental health issues was curvilinear suggests age remains a useful yet more nuanced predictor than deemed by the past literature. As increasingly inconsistent results on mental health during COVID-19 are reported, we call for more studies to examine the nonlinear relationships of the predictors of mental health issues. 


\section{Appendix. Measurement scales}

\section{PHQ-4: Anxiety and Depression}

Over the last week, how often have you been bothered by the following problems?

\begin{tabular}{|c|c|c|c|c|}
\hline 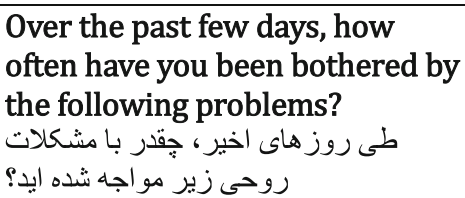 & 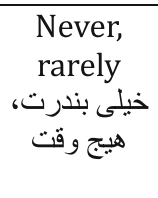 & $\begin{array}{l}\text { Sometimes } \\
\text { بعضى وقتها }\end{array}$ & $\begin{array}{l}\text { most of } \\
\text { time } \\
\text { اكثر اوقات }\end{array}$ & $\begin{array}{l}\text { Always } \\
\text { هميشَه، تمام } 1 \text { اوقات }\end{array}$ \\
\hline $\begin{array}{l}\text { 1. Feeling nervous, anxious or } \\
\text { on edge } \\
\text { احساس عصبانيث، اضطر اب يا ترس }\end{array}$ & 0 & 1 & 2 & 3 \\
\hline 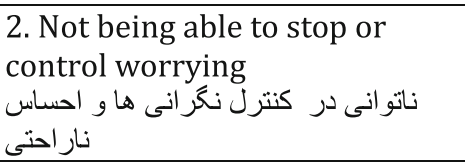 & 0 & 1 & 2 & 3 \\
\hline $\begin{array}{l}\text { 3. Feeling down, depressed or } \\
\text { hopeless } \\
\text { احساس كمبود، افسردكى و ناميدى }\end{array}$ & 0 & 1 & 2 & 3 \\
\hline $\begin{array}{l}\text { 4. Little interest or pleasure in } \\
\text { doing thing } \\
\text { داشتن لذت كم از انجام كار ها }\end{array}$ & 0 & 1 & 2 & 3 \\
\hline
\end{tabular}




\section{Psychological Pain scale}

\begin{tabular}{|c|c|c|c|c|}
\hline For the past few days, I feel & 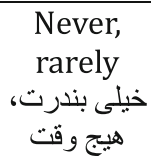 & $\begin{array}{l}\text { Sometimes } \\
\text { بعضى وقتها }\end{array}$ & $\begin{array}{l}\text { most of } \\
\text { time } \\
\text { اكثر اوقات }\end{array}$ & $\begin{array}{c}\text { Always } \\
\text { هميشه، تمام } 1 \text { اوقات }\end{array}$ \\
\hline 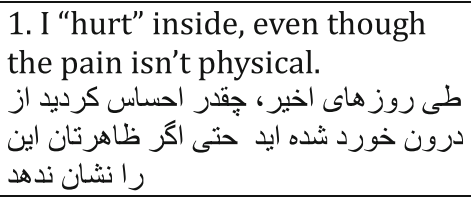 & 0 & 1 & 2 & 3 \\
\hline 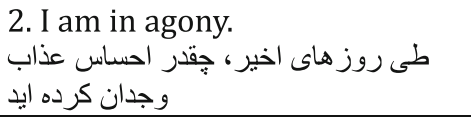 & 0 & 1 & 2 & 3 \\
\hline 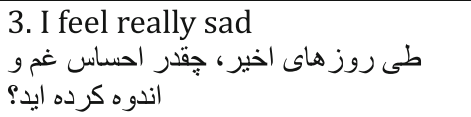 & 0 & 1 & 2 & 3 \\
\hline
\end{tabular}

\section{The Kessler Psychological Distress Scale (K6)}

\begin{tabular}{|c|c|c|c|c|c|}
\hline $\begin{array}{l}\text { During the last few days, } \\
\text { about how often did... } \\
\text { طى روز هاى اخير تا جه اندازه }\end{array}$ & $\begin{array}{l}\text { Never } \\
\text { هركز }\end{array}$ & $\begin{array}{l}\text { Some of } \\
\text { the time } \\
\text { به ندرث }\end{array}$ & $\begin{array}{l}\text { Half- } \\
\text { time } \\
\text { هر جند بن بار }\end{array}$ & $\begin{array}{l}\text { A good bit of } \\
\text { the time } \\
\text { بيشتر اوقات }\end{array}$ & $\begin{array}{l}\text { Almost all } \\
\text { of the time } \\
\text { تمام اوقات }\end{array}$ \\
\hline $\begin{array}{l}\text { 1. You feel worthless? } \\
\text { الحساس بى ارزش بودن كرده }\end{array}$ & 0 & 1 & 2 & 3 & 4 \\
\hline $\begin{array}{l}\text { 2. You feel nervous? } \\
\text { عصبى شده ايد؟ }\end{array}$ & 0 & 1 & 2 & 3 & 4 \\
\hline $\begin{array}{l}\text { 3. You feel restless or } \\
\text { fidgety? } \\
\text { احساس بى قر ارى يا اضطر اب كرد؟ }\end{array}$ & 0 & 1 & 2 & 3 & 4 \\
\hline $\begin{array}{l}\text { 4. You feel hopeless? } \\
\text { احساس ناميدى كرده ايد؟ }\end{array}$ & 0 & 1 & 2 & 3 & 4 \\
\hline 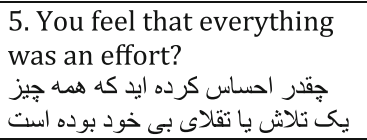 & 0 & 1 & 2 & 3 & 4 \\
\hline 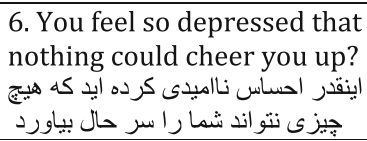 & 0 & 1 & 2 & 3 & 4 \\
\hline
\end{tabular}


Author Contribution J.C.: investigation, formal analysis, writing - original, writing - review and editing

S.X.Z.: conceptualization, investigation, methodology, formal analysis, writing — original, writing - review and editing, supervision

Y.W.: visualization, writing — original, writing — review and editing

A.A.J.: writing - review and editing, investigation (data collection)

M.M.D.: investigation (data collection)

A.N.M.: investigation (data collection)

K.N.: investigation (data collection)

\section{Declarations}

Ethical Approval The study was approved by the ethics committee of Shahid Rajaee Teacher Training University (IR.SSRI.REC.1389.685).

Conflict of Interest The authors declare no competing interests.

Financial Disclosure Nil.

\section{References}

Ahorsu, D. K., Lin, C. Y., Imani, V., Saffari, M., Griffiths, M. D., \& Pakpour, A. H. (2020). The fear of COVID19 scale: development and initial validation. International Journal of Mental Health and Addiction. https:// doi.org/10.1007/s11469-020-00270-8.

Aman, F. (2020). The unique challenges posed by COVID-19 in Iran and Afghanistan - Atlantic Council. Tehran. Retrieved from https:/www.atlanticcouncil.org/commentary/video/the-unique-challenges-posedby-covid-19-in-iran-and-afghanistan/

Chen, X., Zhang, S. X., Jahanshahi, A. A., Alvarez-Risco, A., Dai, H., Li, J., \& Ibarra, V. G. (2020). Belief in a COVID-19 conspiracy theory as a predictor of mental health and well-being of health care workers in Ecuador: cross-sectional survey study. JMIR Public Health and Surveillance, 6(3), e20737. https://doi.org/ $10.2196 / 20737$.

Chen, J., Farah, N., Dong, R. K., Chen, R. Z., Xu, W., Yin, A., Chen, B. Z., Delios, A., Miller, S., Xue, W., \& Zhang, S. X. (2021). The mental health under the COVID-19 crisis in Africa: a systematic review and metaanalysis. MedRxiv, 2021(04), 19.21255755. https://doi.org/10.1101/2021.04.19.21255755.

Cronbach, L. J. (1951). Coefficient alpha and the internal structure of tests. Psychometrika, 16(3), $297-334$. https://doi.org/10.1007/BF02310555.

Dai, H., Zhang, S. X., Looi, K. H., Su, R., \& Li, J. (2020). Perception of health conditions and test availability as predictors of adults' mental health during the covid-19 pandemic: a survey study of adults in Malaysia. International Journal of Environmental Research and Public Health, 17(15), 1-10. https://doi.org/10.3390/ ijerph17155498.

González-Sanguino, C., Ausín, B., Castellanos, M. Á., Saiz, J., López-Gómez, A., Ugidos, C., \& Muñoz, M. (2020). Mental health consequences during the initial stage of the 2020 coronavirus pandemic (COVID-19) in Spain. Brain, Behavior, and Immunity, 87, 172-176. https://doi.org/10.1016/J.BBI.2020.05.040.

Guo, Q., Zheng, Y., Shi, J., Wang, J., Li, G., Li, C., Fromson, J. A., Xu, Y., Liu, X., Xu, H., Zhang, T., Lu, Y., Chen, X., Hu, H., Tang, Y., Yang, S., Zhou, H., Wang, X., Chen, H., Wang, Z., \& Yang, Z. (2020). Immediate psychological distress in quarantined patients with COVID-19 and its association with peripheral inflammation: a mixed-method study. Brain, Behavior, and Immunity, 88, 17-27. https://doi.org/10.1016/J. BBI.2020.05.038.

Jahanshahi, A. A., Dinani, M. M., Madavani, A. N., Li, J., \& Zhang, S. X. (2020). The distress of Iranian adults during the Covid-19 pandemic - more distressed than the Chinese and with different predictors. Brain, Behavior, and Immunity, 87, 124-125. https://doi.org/10.1016/J.BBI.2020.04.081.

Keller, M., \& Nesse, R. (2006). The evolutionary significance of depressive symptoms: different adverse situations lead to different depressive symptom patterns. Journal of Personality and Social Psychology, 91(2), 316-330. https://doi.org/10.1037/0022-3514.91.2.316.

Kessler, R. C., Andrews, G., Colpe, L. J., Hiripi, E., Mroczek, D. K., Normand, S. L. T., et al. (2002). Short screening scales to monitor population prevalences and trends in non-specific psychological distress. Psychological Medicine, 32(6), 959-976. https://doi.org/10.1017/S0033291702006074. 
Khademian, F., Delavari, S., Koohjani, Z., \& Khademian, Z. (2021). An investigation of depression, anxiety, and stress and its relating factors during COVID-19 pandemic in Iran. BMC Public Health, 21(1), 275. https:// doi.org/10.1186/s12889-021-10329-3.

Kroenke, K., Spitzer, R. L., Williams, J. B. W., \& Lowe, B. (2009). An ultra-brief screening scale for anxiety and depression: the PHQ-4. Psychosomatics, 50(6), 613-621. https://doi.org/10.1176/appi.psy.50.6.613.

Liu, C. H., Zhang, E., Wong, G. T. F., Hyun, S., \& Hahm, H. C. (2020). Factors associated with depression, anxiety, and PTSD symptomatology during the COVID-19 pandemic: clinical implications for U.S. young adult mental health. Psychiatry Research, 290, 113172. https://doi.org/10.1016/j.psychres.2020.113172.

Meng, H., Xu, Y., Dai, J., Zhang, Y., Liu, B., \& Yang, H. (2020). Analyze the psychological impact of COVID19 among the elderly population in China and make corresponding suggestions. Psychiatry Research, 289, 112983. https://doi.org/10.1016/J.PSYCHRES.2020.112983.

Moccia, L., Janiri, D., Pepe, M., Dattoli, L., Molinaro, M., De Martin, V., et al. (2020). Affective temperament, attachment style, and the psychological impact of the COVID-19 outbreak: an early report on the Italian general population. Brain, Behavior, and Immunity, 87, 75-79. https://doi.org/10.1016/J.BBI.2020.04.048.

Moghanibashi-Mansourieh, A. (2020). Assessing the anxiety level of Iranian general population during COVID19 Outbreak. Asian Journal of Psychiatry, 51(3), 102076. https://doi.org/10.1016/j.ajp.2020.102076.Qiu.

Ni, MY., Yang, L., Leung, CMC., Li, N., Yao, XI., Wang, Y., Leung, GM., Cowling, BJ., Liao, Q. (2020). Mental Health, Risk Factors, and Social Media Use During the COVID-19 Epidemic and Cordon Sanitaire Among the Community and Health Professionals in Wuhan, China: Cross-Sectional Survey. JMIR Ment Health. 127(5):e19009. https://doi.org/10.2196/19009.

Song, K., Xu, R., Stratton, T., Kavcic, V., Luo, D., Hou, F., et al. (2020). Sex differences and psychological stress: responses to the COVID-19 epidemic in China. MedRxiv, 2020(04), 29.20084061. https://doi.org/10. 1101/2020.04.29.20084061.

Tang, P. M., Zhang, S. X., Li, C. H., \& Wei, F. (2020). Geographical identification of the vulnerable groups during COVID-19 crisis: psychological typhoon eye theory and its boundary conditions. Psychiatry and Clinical Neurosciences, 74(10), 562-563. https://doi.org/10.1111/pcn.13114.

Twenge, J., \& Joiner, T. (2020). Mental distress among U.S. adults during the COVID-19 pandemic. https://doi. org/10.31234/OSF.IO/WC8UD.

Wang, H., Xia, Q., Xiong, Z., Li, Z., Xiang, W., Yuan, Y., Liu, Y., \& Li, Z. (2020). The psychological distress and coping styles in the early stages of the 2019 coronavirus disease (COVID-19) epidemic in the general mainland Chinese population: a web-based survey. PLoS One, 15(5), e0233410. https://doi.org/10.1371/ journal.pone.0233410.

Xiang, Y.-T., Yang, Y., Li, W., Zhang, L., Zhang, Q., Cheung, T., \& Ng, C. H. (2020). Timely mental health care for the 2019 novel coronavirus outbreak is urgently needed. The Lancet Psychiatry, 7(3), 228-229. https://doi.org/10.1016/S2215-0366(20)30046-8.

Yáñez, J. A., Jahanshahi, A. A., Alvarez-Risco, A., Li, J., \& Zhang, S. X. (2020). Anxiety, distress, and turnover intention of healthcare workers in Peru by their distance to the epicenter during the COVID-19 crisis. American Journal of Tropical Medicine and Hygiene, 103(4), 1614-1620. https://doi.org/10.4269/ajtmh.20-0800.

Yoosefi Lebni, J., Abbas, J., Moradi, F., Salahshoor, M. R., Chaboksavar, F., Irandoost, S. F., Nezhaddadgar, N., \& Ziapour, A. (2020). How the COVID-19 pandemic effected economic, social, political, and cultural factors: a lesson from Iran. International Journal of Social Psychiatry, 67, 298-300. https://doi.org/10.1177/ 0020764020939984.

Zhang, J., Lu, H., Zeng, H., Zhang, S., Du, Q., Jiang, T., \& Du, B. (2020a). The differential psychological distress of populations affected by the COVID-19 pandemic. Brain, Behavior, and Immunity, 87, 49-50. https://doi.org/10.1016/J.BBI.2020.04.031.

Zhang, S. X., Chen, J., Jahanshahi, A. A., Alvarez-Risco, A., Dai, H., Li, J., \& Patty-Tito, R. (2020b). Succumbing to the COVID-19 pandemic: healthcare workers not satisfied and intend to leave their jobs. MedRxiv, 2020(05), 22.20110809. https://doi.org/10.1101/2020.05.22.20110809.

Zhang, S. X., Wang, Y., Rauch, A., \& Wei, F. (2020c). Unprecedented disruption of lives and work: health, distress and life satisfaction of working adults in China one month into the COVID-19 outbreak. Psychiatry Research, 288, 112958. https://doi.org/10.1016/J.PSYCHRES.2020.112958.

Zhang, S. X., Liu, J., Afshar Jahanshahi, A., Nawaser, K., Yousefi, A., Li, J., \& Sun, S. (2020d). At the height of the storm: healthcare staff's health conditions and job satisfaction and their associated predictors during the epidemic peak of COVID-19. Brain, Behavior, and Immunity, 87, 144-146. https://doi.org/10.1016/j.bbi. 2020.05.010.

Publisher's Note Springer Nature remains neutral with regard to jurisdictional claims in published maps and institutional affiliations. 


\section{Affiliations}

Jiyao Chen ${ }^{1} \cdot$ Stephen X. Zhang ${ }^{2} \cdot$ Yifei Wang $^{3} \cdot$ Asghar Afshar Jahanshahi $^{4,5} \cdot$ Maryam Mokhtari Dinani $^{6} \cdot$ Abbas Nazarian Madavani $^{7} \cdot$ Khaled Nawaser $^{8}$

Jiyao Chen

Jiyao.chen@oregonstate.edu

Yifei Wang

zzxcwyf@163.com

Asghar Afshar Jahanshahi

afsharasghar@gmail.com

Maryam Mokhtari Dinani

m.mokhtaridinani@Alzahra.ac.ir

Abbas Nazarian Madavani

abbasnazarian@sru.ac.ir

Khaled Nawaser

khalednawaser56@gmail.com

1 Oregon State University, 416 Austin Hall, Corvallis, OR, USA

2 University of Adelaide, 9-27 Nexus10 Tower, 10 Pulteney St, Adelaide, SA 5000, Australia

3 Tongji University, Shanghai, China

4 CENTRUM Católica Graduate Business School (CCGBS), Lima, Peru

5 Pontificia Universidad Católica del Perú (PUCP), Lima, Peru

6 Department of Sport Management, Faculty of Sport Sciences, Alzahra University, Tehran, Iran

7 Department of Sport Management, Faculty of Sport Sciences, Shahid Rajaee Teacher Training University, Tehran, Iran

8 Institute of Scientific Research and Graduate School, Universidad de Lima, Lima, Peru 